\title{
Turistlerin Özgünlük Algısı Üzerinde Bireyci Değerlerin Etkisi
}

\section{The Effect of Individualism on The Tourists' Authenticity Perceptions}

\author{
Dr. Öğr. Üyesi Hakan Sezerel \\ Doç. Dr. Deniz Karagöz \\ Anadolu Üniversitesi \\ Anadolu Üniversitesi \\ Turizm Fakültesi, Eskişehir, Türkiye \\ E-posta: hakansezerel@anadolu.edu.tr \\ Turizm Fakültesi, Eskişehir, Türkiye \\ E-posta: dkaragoz@anadolu.edu.tr
}

Öz

Bireylerin turizme katılımlarında evrensel değerlerin yanında, içinde yaşadıkları kültüre özgü değerler de etkili olmaktadır. Öte yandan, alanyazında turist davranışlarını açıklamada temel bir konu olan özgünlük (otantisite) konusunun kültürel bağlamına ilişkin görgül çalışmalar sınırlıdır. Bu çalışmada, söz konusu eksikliği gidermek için, turistlerin özgünlük algısı üzerindeki bireyci değerlerin etkisi incelenmektedir. Bu amaçla, çalışmada bir kavramsal bir model kurulmuş, Kapadokya Bölgesi'ni ziyaret eden 674 yabancı turistten sağlanan veriler analiz edilmiştir. Araştırmada demografik ve tanımlayıcı verilerin analizinde SPSS 16.0, ölçüm modeli ve kavramsal modelin analizinde ise SmartPLS 3.1. kullanılmıştır. Araştırma sonucunda, bireyci değerlere sahip olmanın objeye dayalı özgünlük ve varoluşsal özgünlük algıları üzerinde anlamlı bir etkisi olduğu saptanmıştır. Buna ek olarak, özgünlüğün turist tatmini üzerinde etkili olduğu, tatminin ise davranışsal niyetleri yordadığı belirlenmiştir.

Anahtar Kelimeler: Özgünlük, Kültür, Uluslararası turist davranışları, Bireycilik, Tatmin, Davranışsal Niyet.

\begin{abstract}
Besides the universal values, the cultural context that the tourists are embedded makes an impact on tourism involvement. In other respects, the empirical research on the cultural context of authenticity in the relevant literature. This paper attempts to fill this specific literature gap by examining the effects of individualist values on authenticity perceptions of tourists. To that end, a conceptual model was designed and analyzed via the data obtained from 674 international tourists who visited Cappadocia Region. When the demographic and descriptive analysis was done by SPSS 16.0, SmartPLS 3.1 was employed to analyze the conceptual model. We found that individualism affects object-based and existentialist authenticity perceptions of tourists. Additionally, the paper reports the effects of authenticity on tourist satisfaction and the satisfaction predicted the behavioral intentions of tourists.
\end{abstract}

Key Words: Authenticity, Culture, International Tourist Behaviors, Individualism, Satisfaction, Behavioral Intentions.

\footnotetext{
${ }^{*}$ Bu çalışmanın özet metni, 4th International Tourism Congress - ITC2019 Kongresi'nde "Horizontal Individualism, Authenticity, and International Tourist Behaviors” başlığıyla sözlü bildiri olarak sunulmuştur. Bu çalışma, Anadolu Üniversitesi Bilimsel Araştırma Projeleri Birimi tarafından desteklenen $1606 E 532$ numaralı “Varoluşsal Özgünlük ve Objeye Dayalı Özgünlük ile Davranışsal Niyet Arasındaki Ilişki Üzerinde Bireycilik Boyutunun Düzenleyici Etkisinin Incelenmesi” başlıklı projeden türetilmiştir.
} 


\section{Giriş}

Turizm yazınında ilk kez uyarlanmasının ardından kırk yılı aşkın bir zaman geçmesine karşın (Maccanell, 1973), özgünlük alanındaki çalışmaların güncelliğini koruması, turizmde özgünlüğe atfedilen merkezi konum ile ilişkilidir (Urry, 1990). Özgünlük; gerçek olma, güvenilir olma, orijinal olma, aracısız olma, hakiki olma ile kopya, yeniden üretilmiş veya orijinali tekrar etmiş olmama, kavramlarıyla tanımlanmaktadır (Ram vd., 2016:111). Diğer bir ifadeyle özgünlük, bireylerin kendileriyle ve dış dünyadaki objelerle ilgili algı, tutum, kavrayış ve deneyimlerinde kendilerine özgülük ve varoluş (Being) halini aradıkları bir yaşantıdır (Knuddsen vd., 2016). Özgünlük kavramı, özgünlüğün algılanışı ve turist davranışlarında özgünlüğün etkileri güncel araştırma konuları olmayı sürdürmektedir.

Turizm alanındaki ilk özgünlük çalışmaları, özgünlüğün anlamına ve turistik deneyime odaklanmakla birlikte görgül araştırmalar arttıkça, yazında bir çeşitlenme olduğu görülmektedir. Alanyazındaki bu çeşitlilik, bireyin özgünlük algılarını belirleyen kültürel ve toplumsal ögelerin ele alınması gerekliliğini beraberinde getirmektedir. Örneğin, Peterson (2005) özgünlük algılarının etnisite, kültürel kimlik ve sosyal statü tarafından belirlendiğini öne sürmüştür. Aynı doğrultuda, Steiner ve Reisinger (2006) özgünlük algılarını açığa çıkarmada; endişe, anlam yaratma, kimlik ve bireycilik gibi değişkenlerin incelenmesini önermektedir. Özetle, özgünlük algısını kavrayabilmek için bireysel ve kültürel özelliklerin anlaşılması önem kazanmaktadır. Yazında farklı ülke ve coğrafyalardan gelen turistlerin özgünlükle ilgili beklenti ve deneyimleri konusunda değerlerini karşılaştıran araştırmalara intiyaç duyulduğu belirtilmektedir (Brida vd., 2017). Alanyazın taramasında da görüleceği gibi özgünlük arayışının daha çok bireyci kültürel değerlerle ilişkili olduğuna yönelik varsayımlar bulunmaktadır (Kim ve Lee, 2000; Peterson, 2005; Yeoman vd., 2007). Buradan hareketle, bu çalışmada, bireyciliğin özgünlük algıları ile ilişkisinin olup olmadığının görgül olarak sınanmasının anlamlı olacağı düşünülmüştür.

Turizm alanyazınında turist davranışlarını anlamak ve açıklamak için kültürel teoriye başvurulduğu ve yerel-evrensel etkileşiminin incelendiği gözlenmektedir (Pizam ve Sussmann, 1995; Reisinger ve Crotts, 2010; Reisinger ve Turner, 2003; Litvin vd. 2004; Lee ve Sparks, 2007). Buradan hareketle, kültürel teoriye başvurarak, yerel ve evrensel arasındaki etkileşim ile farklı kültürel geçmiş yaşantılardan gelen toplulukların seyahat ve turizme yönelik tercihlerini anlamanın özgünlük çalışmaları için bir açılım sağlayacağı düşünülmektedir.

Algılanan özgünlüğe yönelik yapılan alanyazın incelemesinde, turistlerin bireycilik değerlerinin özgünlük üzerindeki etkilerini ele alan kültürlerarası turizm araştırmalarının sınırlı olduğu görülmüştür. Bu nedenle çalışmada, özgünlük algılamalarında bireycilik değerinin rolüne ilişkin saptanan yazınsal boşluğu gidermek üzere kavramsal bir model geliştirilmiştir. Model aracılığıyla, bireycilik değerleri ile özgünlük algıları arasındaki ilişkinin incelenmesi amaçlanmıştır. Buna ek olarak, özgünlük algılarının turist tatmini üzerindeki etkileri ile tatminin davranışsal niyetlere ilişkin etkileri de görgül olarak sınanmıştır. Çalışmanın kuramsal katkısının yanı sıra, turizm planlaması ve politikası başta olmak üzere uygulamaya yönelik katkı sunacağı düşünülmektedir.

Çalışmanın izleyen bölümlerinde, araştırmanın değişkenlerine yönelik yazın taraması ile hipotezlerin geliştirilmesinin ardından yöntem bölümüne yer verilmektedir. Bulgular bölümünde ise tanımlayıcı bulgular ile kuramsal modele ilişkin bulgular yer 
almaktadır. Tartışma ve sonuç bölümünde ise çalışmadan elde edilen bilgilere ve ilerideki araştırmalara yönelik önerilere yer verilmiştir.

\section{Alanyazın}

\section{1. Özgünlük}

Özgünlük konusunun gündeme gelişi, modernitenin sorunlarıyla ilişkilendirilmektedir. Endüstrileşen toplumların daha saf, dokunulmamış, değişmemiş, endüstrileşmemiş, bozulmamış gibi sıfatlarla niteledikleri özgünlük, modern olmayan toplumlar ve coğrafyalarda aranır hale gelmiş ve arayış, kaçış, yabancılaşmadan sıyrılma ve öze dönme gibi kavramlarla ilişkilendirilmiştir (Maccanel, 1999; Wang, 1999; Hall, 2007; Cohen, 2010). Özgünlük konusunda ilk kuramsal çalışmaları sunan Maccanell (1999:11) Veblen'in (2003) modern yaşamda temel bir rol atfettiği farklılaşma (differentation) perspektifinden yararlanmıştır (Korstanje, 2013: 102). Veblen'e göre (2003); cinsiyet, cinsel yönelim, sınıfsal konum ve boş zaman tercihlerinde farklılaşma yaratmak sosyal sınıfların temeli ve modern toplumda seçeneklerin ve özgür yaşamın kökenidir. Maccanell'in The Tourist kitabının alt başlığında da (The New Theory of Leisure Class) Veblen'e açık bir gönderme yapılmaktadır. Maccanell, bu farklılaşmayı ele alarak, postmodernizmin prototipi olan turistlerin davranışlarını - özgünlük bağlamında- açıklamaktadır (Guedez ve Jimenez, 2015).

Özgünlüğü, tarihsel ve sosyolojik bağlamından uyarlamak, turizm alanyazınında bir turist motivasyonu olarak değerlendirmek ve turistin davranışsal niyetleriyle ilişkilendirmek ise, turizm planlalaması, yönetimi ve pazarlaması için önemli bir konu haline gelmiştir. Özgünlük arayışının bu pragmatik incelemesi, farklı turizm bağlamlarında; turistlerin belirli bir destinasyonu ziyaretlerinde ve deneyimlerinde, özgünlük algılarının etkili olduğuna yönelik görgül kanıtlar sunmaktadır. Sözgelimi, Casteran ve Roeder (2013: 160) özgünlük algısının hem turistik etkinliklere yönelik sadakat hem de ziyaret sıklığını; Kolar ve Zabkar (2010) davranışsal niyetleri etkilediğini, Ramkinsoon ve Uysal (2011) kültürel ürünlerin tüketimine yönelik davranışsal niyetlerine olumlu yönde etki ettiğini saptamıştır. Meng ve Choi (2016), turistlerin özgünlük algılarının yavaş turizme yönelik davranışsal niyetler üzerindeki anlamlı etkilerini belirlemiştir.

Turistler özgünlük arayışına girmekte ve başka insanların hayatlarına katılmaya çalışmaktadır. Temeldeki motivasyon ise, yabancılaşmadan kaçınma ve otantik deneyimleri arzulamadır (Olsen, 2002: 160). Urry ise, (1990: 31-33) özgünlük arayışının turizm örgütlenmesinin temeli olduğunu söylemenin doğru olmayacağını ileri sürmektedir. Ona göre, günlük deneyimle oluşturulan zıtlık turizmi değerli kılar. Bu anlamda, turistler otantik olmadığını bildikleri halde turizmden haz almaktadır. Bu haz sıradan ile sıra dışı arasındaki farktan doğmaktadır. Her ne kadar, özgünlüğün merkezi bir konumda olmadığını iddia etse de, yaptığı belirleme özellikle aşağıda değinilecek olan objeye dayalı özgünlükle büyük ölçüde uyumludur. Diğer bir ifadeyle, sıradan ve sıradışı arasındaki fark çoğu zaman, turistlerin objelere atfettikleri özgünlükten ortaya çıkmaktadır.

Hall (2007: 1140) özgün eserlerin güvenliği ve korunması gibi nedenlerle replikasyonlarının sergilendiği durumlarda ziyaretçilerin buna karşın sınırlı da olsa orjinale benzer bir deneyim yaşadıklarını hatta ötesinde kimi zaman replikasyonların günlük yaşamın bir parçası haline gelerek özgünlük kazandıklarını belirtmektedir. Bu anlamda, bir objenin özgünlüğü turistik deneyimleri açıklamada sınırlı kalmaktadır (Wang, 1999: 350). Buna koşut olarak Reisinger ve Steiner (2006) özgünlüğün 
turistlerin turistik bir çekiciliğin özgün olmadığını bildikleri halde dahi, yaşadıkları deneyimlere bağlı olarak oluşabildiğini ve bu özel durumun, varoluşsal özgünlük ile ilgili olduğunu belirtmektedir. Özetle, özgünlük araştırmaları objeye dayalı özgünlük ve varoluşsal özgünlük olmak üzere iki başlık altında yürütülmektedir.

Objeye dayalı özgünlük boyutunun varsayımı, turistlerin objeye dayalı özgünlükte kusursuz, saf ve hakiki olanı aramalarıdır. Objeye dayalı özgünlük, orijinal objelerle kurulan özgünlük ilişkisine odaklanmakta ve yerel ürünlerin kendilerine özgü olma derecelerini ayırt etmektedir. (Wang, 1999; Brida vd., 2013).

Kolar ve Zabkar'a göre (2010: 655), objeye dayalı özgünlük ile varoluşsal özgünlük arasında etkileşim olmasına rağmen boyutlar birbirlerinden ayrışmaktadır. Objeye dayalı özgünlük, orijinal sit alanlarını ziyaret etmek ve eserleri görme, özgün olduğu düşünülen eşyalar satın alma ve gidilen yere özgü objeler, el sanatlarına yönelik deneyim, bilgi ve haz yaşama arzusuyla ilişkilendirilmektedir. Buradan hareketle, objeye dayalı özgünlük, özgünlük deneyiminin ayrılmaz bir parçasıdır. Turistlerin özgünlük deneyimi de, gidilen yerin kendine özgü bileşenleri tarafından etkilenmektedir. Sözgelimi, Belhassen vd. 2008) hac deneyimi ve özgünlük arasındaki ilişkileri inceledikleri çalışmada, hac deneyiminin varoluşsal rolü kadar, hac merkezlerinin mekânsal bileşenlerinin de özgünlük deneyimi algılarında etkili olduğunu saptamıştır. Benzer biçimde, Lin (2015: 23) algılanan özgünlükte doğal peyzajın önemli bir rol olduğunu belirtmektedir.

Cohen (1988:378) ise, özgünlüğü turistlerin belirli turistik modlarına göre konumlandırmaktadır. Söz konusu modlar etik değerlere dayanmakta ve "farklı insanlar turistik deneyimin farklı modlarını arzulamaktadır". Buna göre, özgünlük algıları da turist tiplerine göre değişmektedir. Turistlerin ancak çok küçük bir kısmı (deneyci ve varoluşçu tipler) gerçekten özgünlükle ilgilenmektedir. Bu özel tipler ancak turistler için üretilen ürünlerin özgünlüğü konusunda ikna olurlarsa söz konusu ürünleri almayı kabul etmektedir (el yapımı olan ürünler, yerel kostümlerle yapılan yerel danslar gibi). Özetle, belirli bir modda da bulunsalar, farklı geçmiş yaşantılardan da gelmiş olsalar, objeye dayalı özgünlük algılarının turistler için toplam turizm deneyimlerinde göz ardı edilemez bir yeri bulunmaktadır. Dolayısıyla, özgünlük algılarının oluşumunda, orijinal ya da yerel ürünler kadar, turistlerin yaşadığı deneyimler de etkili görünmektedir. Bu deneyimlerin biçim ve içeriği ise, genel olarak varoluşsal özgünlük kavramıyla karşılanmaktadır. Varoluşsal özgünlük doğası gereği, bir deneyimi yaşayan birey merkezlidir. Varoluşsal özgünlük durumu bireyi, günlük yaşamında sıkça karşılaşmadığı etkinliklere katılmaya teşvik etmekte ve olağan kalıplarından özgürleştirmektedir (Yi vd., 2018: 414). Görüldüğü gibi, objelerle bağıntılı ya da

bağıntısız olarak turistlerin varoluşsal özgünlüğü deneyimleme olanakları bulunmaktadır. Özetle, varoluşsal özgünlüğün deneyimlenmesinin belirli birtakım bireysel koşulları bulunmaktadır. Bu araştırmada, bu koşullardan birinin de kültürel bağlam olduğu ve bireycilik değerlerinin bu bağlam içinde etkili olduğu iddia edilmektedir.

\subsection{Bireycilik}

Özgünlük algısının hangi bağlamda ele alınması gerektiği, kimi zaman bulanık ve belirsiz olabilmektedir. Özgünlük yazınında özetlendiği gibi, bireysel ve toplumsal farklılıklar bireylerin özgünlük algılarını etkileyebilmektedir. Diğer bir deyişle, kimi turistin özgün ve orijinal bulduğu belirli objeler diğerleri tarafından bulunmamaktadır (Yi vd., 2018: 412). Sosyal bilimlerde, birey ve grup davranışlarının açıklanmasında, kültürel bağlamın belirleyici olduğu iddia edilmektedir. Bu çalışmada, turistlerin 
bireycilik algıları ile özgünlük algıları arasındaki ilişki arandığından, kültürlerarası araştırmalara yönelik alanyazın taranmış ve (Hofstede, 1980; 2001; 2005; Javidan vd., 2006; Trompenaars ve Turner, 2011) turizm araştırmacılarının bireycilik konusunu incelerken ülkesel karşılaştırmalar için Hofstede'nin (1980, 2001, 2005) çalışmalarını temel aldıkları görülmüştür (Matzler vd., 2016; Huang ve Crotts, 2019).

Bireycilik ya da toplulukçuluk çalışmalarında ana kaynak Hofstede'nin (1980) çalışmasıdır. Bu çalışma belirli bir işletmede çalışan bireylerden elde ettiği verileri, ülkelere genellemektedir. Araştırmada, ülke karşılaştırmasını mümkün kılmak için bir ülkedeki bireylerden toplanan veriler o ülkeyi temsil edecek biçimde derlenmiştir. Diğer bir ifadeyle, analiz düzeyi, bireyler değil, ülkelerdir. Bireycilik Hofstede (1980) tarafından; belirli bir toplumda görülen davranışları diğer toplumlardan ayrıştırmak için en önemli değişkenlerden biri olarak görülmektedir. Bireyci toplulukların üyeleri; özerkliğe, duygusal bağımsızlığa ve evrenselci olmaya eğilimlidir. Bunun tersine, düşük bireyci topluluklarda (toplulukçu) grup kimliği ile grup dayanışmasını öne çıkarma, kaynakların etkin paylaşımı ve partikülarizm yaygındır (Hofstede ve Hofstede, 2005). Triandis (2001) bireycilik ve toplulukçuluğu kesen dikey ve yatay perspektiflerden yararlanarak geliştirdiği modelde, Hofstede'nin (1980) toplum üyelerini ayırt eden güç dağılımı boyutu olan güç mesafesinin kavramsal akrabası olan (Triandis, 2001: 39) dikey ve yatay kültürleri önermektedir. Hofstede'nin çalışmasında bireycilik ve toplulukçuluk birbirine karşıt iki boyut olarak düşünülürken Triandis modelinde, her bireyde hem bireyci hem de toplulukçu ögelerin baskınlığından söz edilmektedir (Uçar ve Konal, 2017:983). Buna göre, kişiler için bireycilik algısı güç konusundaki pozisyonlarına göre farklılaşmaktadır. Değişik türdeki bireycilikleri ayırt eden en önemli özelliklerden birisi, yatay ya da dikey perspektiflerin benimsenmesidir. Yatay kültürler eşitliğe vurgu yaparken, dikey kültürler hiyerarşiyi temel almaktadır. Bu nedenle, yatay bireycilikte, "tüm insanlar eşit" fakat " her birey eşsiz" dir. Dikey bireycilikte ise, hem farklılaşma hem de göreli olarak diğerlerine göre "en iyi olma" üzerine odaklanılmaktadır (Triandis, 2001: 36). Yatay bireycilik özellikleri gösteren birey ve/veya topluluklarda özgünlük ve bağımsızlık öne çıkmakla birlikte, statüye dayalı farklılaşma eğilimi bulunmamaktadır. Bunun karşısında, dikey bireyci toplumlarda öne çıkan değerler ise; rekabet, kazanmak ve statüdür (Kağıtçıbaşı, 1997; Wasti ve Erdil, 2007).

Toplumlarda bireycilik ya da toplulukçuluk için benimsenen değer, kendine özgü yanlara sahiptir. Sözgelimi, bireycilik Amerikalılar ve İsveçliler için farklı anlamlara gelebilirken; toplulukçuluk algıları Koreliler ve İsrailliler için farklı anlamlara gelebilmektedir (Triandis ve Gelfand, 1998: 119). Triandis toplumsal kültürün bireyde de yansıdığını ve bireycilik değerinin özerk benlikle, toplulukçuluk değerinin ise ilişkisel benlikle karakterize edildiğini belirtmektedir. Özerk benliğe sahip olan kişilerde yetenekleri, tutumları, intiyaç ve beklentileri ile tercihlerinin davranışlarına etki ettiği ve özerkliğin ön planda olduğu kişiler için diğerlerinden farklılaşmak, otantik olmak ve amaçlarını gerçekleştirmek önemli olmaktadır (Markus ve Kitayama, 1991; Wasti ve Erdil, 2007).

Bireyciliğin turizm alanındaki karşılığı ise bireyci toplum üyelerinin kitle turizminden ziyade bireysel turizm etkinliklerine katılmalarıdır (Litvin ve Kar, 2003). Bireycilik boyutu, bireyler için kişisel intiyaçlara vurgu yapmaktadır. Başka bir ifadeyle, kişinin bireysel beklenti ve intiyaçlarını, bağlı olduğu grubun beklenti ve intiyaçlarına üstün tutup tutmadığıdır. Bireyci kültürlerde kişisel amaçlar, haklar ve ihtiyaçlar önceliklidir. Turizm davranışı bağlamına tercüme edildiğinde; özgürlük, başarı, özerklik, inisiyatif alma, bireysel kararlar verme, finansal güvenlik ve kendini gerçekleştirme öne çıkmaktadır. Bireyler öz yönelimlidir ve özel yaşamları ile kendini gerçekleştirmeye 
önem vermektedir. Düşük bireycilikte ise, grup amaç, hak ve ihtiyaçları öne çıkmaktadır. Kararlar konsensüs ve işbirliğine dayalıdır. Sosyal bağlar, kişisel girişimlerden önce gelmektedir. Bu özellikler, turizm etkinliklerine yönelik seçimlerde de etkili olmaktadır. Örneğin, Pizam ve Fleisher (2005:12-13) yüksek düzeyde bireyci kişilerin dinamik, etkin ve kendini yansıtan (örn: avcılık, balıkçılık, rafting, vahşi doğa yürüyüşü gibi) etkinliklere yöneleceğini, düşük bireyci değerlere sahip kişilerin ise, sosyalleşmeyi öne alan (kültür ve sanat sergileri, tiyatro ve bale, arkadaş ve akraba ziyaretleri gibi) etkinlikleri tercih edeceğini öne sürmüştür.

Pizam ve Jeong (1996) ulusal kültürlerin turistik kültürlere baskın olduğunu belirtmektedir. Örneğin, bazı ulusların (örn: Amerikalılar) bireyciliğe ve dışa dönüklüğe daha yatkın, bazı ulusların ise grup içinde yer almaya ve akrabalığa daha fazla önem veren (örn: Japonlar), toplulukçu bir yapıda olduklarını belirtmektedir. Pizam ve Sussman (1995: 113) aynı doğrultuda, özgünlük ile ilgili turist tercihlerinin farklı uluslardan gelme nedeniyle farklılaştığını öne sürmektedir. Fransız, Amerikan ve İtalyanlar (bireyci kültürler) "gerçek" özgünlüğü ararken; Japon turistler "sahnelenen" özgünlükten tatmin olmaktadır. Buna ek olarak; yalnız ya da bir grupla seyahat etmek de, bireycilik boyutu tarafından belirlenmektedir. Düşük bireyci ya da toplulukçu toplumlardan gelen bireyler; yaşayacakları olası kültür şokunun yoğunluğunu azaltmak için grupla seyahati tercih etmektedir. Bu durum toplulukçu değerleri yüksek bireyler için bir güven duygusu sağlamaktadır (Pizam ve Sussman, 1995: 113).

Yeni deneyimler yaşama arayışı; özgünlük ve özgün olanı arama ise yüksek bireycilikle ilişkilendirilmiştir (Kim ve Lee, 2000:157; Yeoman vd., 2007: 1131-1132, Peterson, 2005). Yeoman vd. (2007:1131) özgün turisti yönlendiren eğilimin bireycilik olduğunu belirtmektedir. Turistler, yalnızca geleneksel köklerden değil; (aile, yerel ve ulusal bağlılıklar), yaşam tarzı, marka bağlılığı ve niş ilgilerden kendilerini gerçekleştirmek, kimliklerini bulmak ya da yeni bir kimlik kazanmak geniş bir yelpazedeki ürün ve hizmetleri talep etmektedir. Öte yandan bu eğilim kuşaklar açısından da güçlenmektedir. Peterson (2005:1094) özgünlük arayışının zamanla geliştiğini ve Berman'a atıf yaparak (1970) radikal bireycilikle ilişkili olduğunu belirtmektedir. Buradan hareketle:

H1: Turistlerin bireycilik değerleri ile varoluşsal özgünlük algıları arasında anlamlı bir ilişki vardır.

H2: Turistlerin bireycilik değerleri ile objeye dayalı özgünlük algıları arasında anlamlı bir ilişki vardır.

\subsection{Tatmin}

Turistlerin bir destinasyonda geçirdikleri yaşantı ya da deneyimleri, o destinasyona özgü özelliklerden ve yaşantılarından sağladıkları tatmini etkilemektedir. Bu nedenle, turist tatmini konusunu özgünlük algıları bağlamında değerlendirmek önem kazanmaktadır. Araştırmalar, kültürel miras alanlarını deneyimlemenin ve yerel etkinliklere katılmanın başlı başına turist tatminini anlamlı biçimde etkilediğini bunun yanında dolaylı olarak destinasyon bağlılığı ve yer bağlılığını arttırdığını saptamaktadır (Lu vd. 2015: 93). Zhou vd., (2018:59) negatif özgünlük kavramını geliştirirken yaptıkları alanyazın incelemesinde, özgünlüğün turist tatmini üzerindeki anlamlı etkisine yönelik görgül araştırmaları sunmaktadır. Benzer biçimde objeye dayalı ve varoluşsal özgünlüğün turist tatminleri üzerinde anlamlı ve pozitif bir etkisi olduğu görgül olarak tespit edilmiştir (Zhang vd., 2018; Dominguez-Quintero vd. 2019). Bu bilgiler ışığında, aşağıdaki hipotezler üretilmiştir: 
H3: Objeye dayalı özgünlük ile turist tatmini arasında anlamlı bir ilişki vardır.

H4: Varoluşsal özgünlük ile turist tatmini arasında anlamlı bir ilişki vardır.

\subsection{Davranışsal Niyet}

Destinasyonların ve turizm işletmelerinin turist tatminini arttırmaya yönelik birincil motivasyonları destinasyona daha fazla ziyaretçi çekerek, daha fazla gelir elde etmektir (Baker ve Crompton, 2000: 790; Adinegara vd., 2017). Bu doğrultuda, tatmin ile tekrar ziyaret ve tavsiye etme davranışları arasındaki ilişki son yıllarda en fazla incelenen konu olmuştur. Turistlerin gittikleri destinasyonu tekrar tercih etmelerinde, duydukları tatminin etkili olduğu güncel pek çok çalışmada saptanmıştır (Eusobio ve Viera, 2013; Hultman vd., 2015; Loi vd., 2017; Meng ve Han 2018). Tatminin davranışsal niyete etki ettiğini saptayan çalışmalara karşın, bu ilişkinin doğrulanmadığı çalışmalar da mevcuttur (Bajs, 2015). Bu veriler ışığında, oluşturulan kavramsal modeli sınamak amacıyla aşağıdaki hipotez geliştirilmiştir.

H5: Turist tatmini ile davranışsal niyetler arasında anlamlı bir ilişki vardır.

\section{Yöntem}

\section{1. Örneklem ve Ölçüm}

$\mathrm{Bu}$ çalışma, Anadolu Üniversitesi Bilimsel Araştırma Projeleri Birimi tarafından desteklenen 1606E532 numaralı "Varoluşsal Özgünlük ve Objeye Dayalı Özgünlük ile Davranışsal Niyet Arasındaki İlişki Üzerinde Bireycilik Boyutunun Düzenleyici Etkisinin İncelenmesi" başlıklı projeden türetilmiştir. Çalışmanın etik kurallara uygunluğu Anadolu Üniversitesi BAP Komisyonu'nca incelenmiştir. Çalışmada, tüm gerekli etik kurallarına dikkat edilmiş, katılımcılara gönüllü katılımcı formu imzalatılmış, bunun yanında sözlü onayları alınmıştır. Bu çalışmada, tesadüfi olmayan örnekleme yöntemlerinden kolayda örnekleme kullanılmıştır. Çalışmanın anketi, 1985 yılında hem kültürel hem de doğal miras olarak UNESCO'nun Dünya Miras Listesi'nde yer alan Kapadokya Göreme Milli Parkı ve Kapadokya'yı ziyaret eden uluslararası turistler ile yapılmıştır. Kapadokya'da yer alan turist noktalarında, park ve diğer çekiciliklerin girişlerinde yer alan dinlenme alanlarında bulunan turistlere uygulanmıştır. Çalışma verilerinin toplanmasında üç farklı dilde (Almanca, İngilizce ve Fransızca) hazırlanan anket kullanılmıştır. Anketlerin hazırlanmasında, bu dillerde eğitim almış uzmanlardan yardım alınmış; çeviri denkliğinin sağlanması amacıyla çeviri-tekrar çeviri tekniğinden faydalanılmıştır. Veriler turistler ile yüz yüze anket tekniği ile Kapadokya için yüksek sezon olarak kabul edilen 2018 Mayıs-Temmuz dönemlerinde toplanmıştır. Kayıp veri düzeyinin yüksek olduğu anketler elendikten sonra toplam 674 kullanılabilir anket veri analizi için kullanılmıştır.

Araştırmanın anket formu iki bölümden oluşmaktadır. Birinci bölümde yanıtlayıcıların demografik özelliklerine ve seyahat şekillerine ilişkin bilgileri ölçmeye dayalı sorular yer almaktadır. İkinci bölümde ise araştırmanın modelini oluşturan değişkenleri ölçmeye dayalı ölçekler bulunmaktadır. Demografik veriler hariç çalışmada incelenen tüm yapılar yedi aralıklı Likert ölçeği (1=kesinlikle katılmıyorum, $7=$ kesinlikle katılıyorum) ile ölçülmüştür. Ayrıca ölçeğin sonunda ifadelere cevap vermek isteyen anket katılımcıları için "fikrim yok" sütunu eklenmiş ve bunlar kayıp veri olarak kodlanmıştır. 
Çalışmada, bireycilik, objeye dayalı özgünlük, varoluşsal özgünlük, tatmin ve davranışsal niyetler boyutları reflektif yapılar olarak ölçülmüştür. Çalışmadaki değişkenler için ölçüm maddeleri önceki çalışmalardan alınmıştır. Bireycilik ölçeği, Triandis ve Gelfand (1998); objeye dayalı özgünlük ve varoluşsal özgünlük, Kolar ve Zabkar'dan (2010) ve Ramkissoon ve Uysal'dan (2011) alınan dokuz madde kullanılarak operasyonelleştirilmiştir. Tatmin boyutu Chen ve Chen'den (2010) alınan üç madde ile ölçülmüştür. Son olarak, davranışsal niyetler Ramkisson ve Uysal (2001) ve Chen ve Tsai'den alınan (2007) dört madde ile ölçülmüştür. Maddelerin modifikasyonu destinasyon yönetimi alanında uzman akademisyenler tarafından gerçekleştirilmiştir. Akademisyenlerin incelemelerine dayalı olarak yapı, açıklık ve kelimelerin yeniden seçimi bakımından yeniden düzenlenerek ankete son hali verilmiştir.

\subsection{Verilerin Analizi}

Araştırmada demografik ve tanımlayıcı verilerin analizinde SPSS 16.0, ölçüm modeli ve yapısal modelin analizinde ise SmartPLS 3.1. kullanılmıştır. Yapısal model analizinde geleneksel yöntem Kovaryansa Dayalı Yapısal Eşitlik Modellemesidir (CBSEM) ancak CBSEM, normallik varsayımı ve büyük örneklem büyüklüğü gereklilikleri gibi çok sayıda kısıtlamaya sahiptir. Bu nedenle çalışmada, önerilen modeli analiz etmek ve incelemek için kısmi en küçük kareler (PLS) tekniği kullanılmıştır. PLS tekniği turizmde CBSEM'e modern bir alternatif olarak (García vd., 2012; Ali vd., 2016) özellikle teori geliştirme ve öngörücü (predictive) uygulamadaki uygunluğu nedeniyle kullanılmaktadır (Chin, 1998). Bu teknik, bağımsız ve bağımlı değişkenler arasındaki ilişkinin sağlamlığını (gücünü-robustness) maksimize eden yapısal modelleri tahmin etmede iteratif prosedür kullanmaktadır. PLS tekniği, dışsal model ve içsel model olarak tanımlanan iki modelden oluşur. Dışsal model, gözlenen ve gizli değişkenler veya yapılar arasındaki ilişkiyi inceler (CBSEM'deki ölçüm modeline benzerdir). İçsel model ise yapılar ya da gizil değişkenler arasındaki ilişkileri test etmektedir (CBSEM'deki yapısal modele benzerdir). Yapısal modelin değerlendirilmesinde CBSEM'deki RMSEA, GFI, CFI gibi kriterlere karşıt olarak PLS tekniğinde yapısal modelin değerlendirlmesinde ise, $R^{2}, \beta$, t-değerleri, Cohen's $f^{2}$ ve $\mathrm{Q}^{2}$ değerleri incelenmektedir. Bu çalışmada, önerilen modelin analizinde Smart PLS 3.1. kullanılmıştır.

\subsection{Bulgular}

\subsection{1. Örneklem Profili ve Tanımlayıcı Bulgular}

Tablo 1: Yanıtlayıcıların demografik özellikleri

\begin{tabular}{lcc}
\hline Değişkenler & & $\%$ \\
\hline Cinsiyet & Erkek & 51,8 \\
& Kadın & 48,2 \\
Yaş & $18-34$ & 56,4 \\
& $35-54$ & 31,8 \\
Eğitim durumu & 55 ve üzeri & 11,8 \\
& Lise & 3,2 \\
\multirow{2}{*}{ Ziyaret durumu } & Lisans & 82,0 \\
& Lisans üstü & 14,8 \\
Seyahat şekli & First time & 89,1 \\
& Repeat visit & 10,9 \\
& Individual & 92,8 \\
\hline
\end{tabular}


Tablo 1'de görüldüğü gibi, anketi yanıtlayanların \% 51,8'i erkek, \% 48,2'si kadındır. Yanıtlayıcıların çoğunluğu $18-34$ yaş $(\% 56,4)$ ve $35-54$ yaş $(\% 31,8)$ aralığında yer almaktadır. Eğitim düzeyleri incelendiğinde ise katılımcıların çoğunluğunun lisans $(\% 82,0)$ ve lisansüstü düzeyde $(\% 14,8)$ eğitim düzeyine sahip oldukları belirlenmiştir. Anketi yanıtlayanların çoğunun Kapadokya'yı ilk kez ziyaret ettikleri $(\% 89,1)$ ve bireysel olarak seyahat ettikleri $(\% 92,8)$ saptanmıştır.

\subsection{2. Ölçüm modelinin değerlendirilmesi}

Bu çalışma, verilerin analizi aşamasında Anderson ve Gerbing'in (1998) ilkelerini takip etmiştir. Buna göre, temel gizli değişkenlerin geçerliliği ve güvenilirliği yapısal model incelenmeden önce ölçüm modelinde doğrulanmıştır. Ölçüm modelinin geçerliliği yakınsak geçerlik ve ayırt edici geçerlilik kullanılarak, güvenilirliği ise Cronbach Alpha ve bileşik güvenilirliği kullanılarak incelenmiştir. Ölçeğin yakınsak geçerliliği, faktör yükleri ve ortalama açıklanan varyans (AVE) değeri kullanılarak incelenmiştir. Tablo 2'de görüldüğü üzere gösterge değişkenlerin tümünün yük değerleri (,752-930),70 eşik değerinin üzerindedir. Yapıların AVE değerleri ise belirtilen 0,50 eşik değerinin üzerindedir (Bagozzi ve Yi, 1988; Tabachnik ve Fidell, 2013) ve bu nedenle ölçeğin yakınsak geçerliliği sağladığı belirlenmiştir. Ölçüm modelinin güvenirliği açısından gösterge ve gizil değişkenlerin Cronbach Alpha ve CR değerlerinin ise önerilen ,70 eşik değerinin üzerinde olduğu belirlenmiştir.

Tablo 2: Ölçüm modeli

\begin{tabular}{lllll}
\hline Yapılar & $\begin{array}{l}\text { Yük } \\
\text { değerleri }\end{array}$ & $\begin{array}{l}\text { Cronbach } \\
\text { Alpha }\end{array}$ & CR & AVE \\
\hline Bireycilik & & 0,856 & 0,890 & 0,670 \\
HI1 & 0,845 & & & \\
HI2 & 0,753 & & & \\
HI3 & 0,883 & & & \\
HI4 & 0,789 & & & 0,783 \\
Objeye Dayalı Özgünlük & & 0,862 & 0,915 & \\
OA1 & 0,774 & & & \\
OA4 & 0,930 & & & \\
OA5 & 0,940 & & 0,595 \\
Varoluşsal özgünlük & & 0,774 & 0,855 & \\
EA1 & 0.752 & & & \\
EA2 & 0.759 & & & \\
EA3 & 0,791 & & & \\
EA4 & 0,783 & & & \\
Tatmin & & 0,796 & 0,879 & \\
SAT1 & 0.896 & & & \\
SAT2 & 0.759 & & & \\
SAT3 & 0.866 & & & \\
Davranışsal Niyet & & & \\
BI1 & 0.791 & 0,906 & 0,909 & \\
BI2 & 0.812 & & & \\
WOM1 & 0.885 & & & \\
WOM3 & 0.890 & & & \\
\hline
\end{tabular}

Yapıların ayırdedici geçerliği üç yaklaşım kullanılarak değerlendirilmiştir. Öncelikle göstergelerin çapraz yük değerleri incelenmiştir. Her bir göstergenin çapraz yük değerlerinin, diğer yapılar üzerindeki çapraz yüklerinden daha yüksek olduğu 
belirlenmiştir. İkinci olarak, Fornell-Locker kriteri (Henseler vd. 2015) kullanılmıştır. Fornell ve Larcker (1981), bir gizil değişken, aynı modeldeki diğer yapılarla paylaştığı gösterge değişkenlerinden daha fazla varyansa sahipse, ayırt edici geçerliğin kurulduğunu öne sürmüşlerdir. Tablo 3 incelendiğinde, her bir yapının AVE değerinin (köşegen değerler) karekökünün, yeterli ayırt edici geçerliliğe karşılık gelen korelasyon katsayılarından daha büyük olduğu görülmektedir. Bu durumda yapıların ayırdedici geçerliğinin tatmin edici olduğu söylenebilmektedir. Üçüncü olarak, Henseler vd.'nin (2015) korelasyonların heterotrait-monotrait oranı (HTMT) yaklaşımı incelenmiştir. Tablo 3 incelendiğinde, yapıların HTMT oranları 0,85 eşik değerinden daha küçüktür (Henseler vd., 2015). Tüm bu bulgular çalışmada ayırdedici geçerlik probleminin bulunmadığını göstermektedir.

Tablo 3: Fornell Locker kriteri bulguları ve HTMT oranları

\begin{tabular}{|c|c|c|c|c|c|}
\hline Yapılar & 1 & 2 & 3 & 4 & 5 \\
\hline Bireycilik & 0,819 & & & & \\
\hline $\begin{array}{l}\text { Davranışsal } \\
\text { niyetler }\end{array}$ & $0,251(0,265)$ & 0,845 & & & \\
\hline $\begin{array}{ll}\text { Objeye } & \text { dayalı } \\
\text { Özgünlük } & \end{array}$ & $0,344(0,401)$ & $0,591(0,656)$ & 0,885 & & \\
\hline Tatmin & $0,349(0,411)$ & $0,617(0,696)$ & $0,617(0,734)$ & 0,842 & \\
\hline $\begin{array}{l}\text { Varoluşsal } \\
\text { özgünlük }\end{array}$ & $0,210(0,253)$ & $0,290(0,350)$ & $0,426(0,520)$ & $0,389(0,495)$ & 0,772 \\
\hline
\end{tabular}

\subsubsection{Yapısal modelin değerlendirilmesi}

Ölçüm modelinin geçerliği ve güvenirliği değerlendirildikten sonra çalışmada, kavramsal modelde öne sürülen hipotezleri test etmek için içsel model, diğer bir deyişle yapısal model incelenmiştir. SmartPLS 3.1 yazılımı kullanılarak gerçekleştirilen SEMPLS yaklaşımında yapısal modeli değerlendirmek için çeşitli kriterler kullanılmıştır. Tüm kriterler 500 resample bootstrapping sürecinde incelenmiştir. Modelin değerlendirilmesinde öncelikle Henseler, Hubona ve Ray'in (2016) önerdiği gibi model uyum kriteri olarak SRMR değeri incelenmiştir. 0,064 SRMR değeri, iyi bir uyum için önerilen 0,10'dan küçük olduğundan bu çalışmada geliştirilen modelin yeterli uyum gösterdiği belirlenmiştir. Ardından Hair vd.'nin önerdiği gibi (2017) her bir içsel gizli değişkenin açıklanan varyansını temsil eden $R^{2}$ değeri incelenmiştir. Bireycilik değişkeni objeye dayalı özgünlüğün \%34'ünü $\left(R^{2}=0,344\right)$, varoluşsal özgünlügün ise $\% 7$ 'sini $\left(R^{2}=0,072\right)$ açıklamaktadır. Varoluşsal özgünlük ve nesneye dayalı özgünlük ise turist tatmininin \% 40 'ını $\left(R^{2}=0,400\right)$ açıklarken; turist tatmini ise davranışsal niyetin $\% 38$ 'ini $\left(R^{2}=0,380\right)$ açıklamaktadır. Şekil 1 ve Tablo 4 incelendiğinde bireycilik ve objeye dayalı özgünlük $(\beta=0,344 ; t=5,081)$ ile varoluşsal özgünlük $(\beta=0,211 ; t=4,624)$ arasındaki yol katsayılarının anlamlı olduğu saptanmıştır ve böylece $\mathrm{H} 1$ ve $\mathrm{H} 2$ kabul edilmiştir. Objeye dayalı özgünlük ile tatmin $(\beta=0,549 ; t=10,314)$ ve varoluşsal özgünlük $(\beta=0,161 ; t=3,966)$ ile tatmin arasında anlamlı bir ilişki olduğu belirlenmiş, dolayısıyla $\mathrm{H} 3$ ve $\mathrm{H} 4$ hipotezleri kabul edilmiştir. Ayrıca turistlerin tatminleri ile davranışsal niyetleri arasındaki ilişkinin de anlamlı olduğu belirlenmiştir $(\beta=0,617$; $t=16,682)$. 
Şekil 1: Yapısal model (t-değerleri)

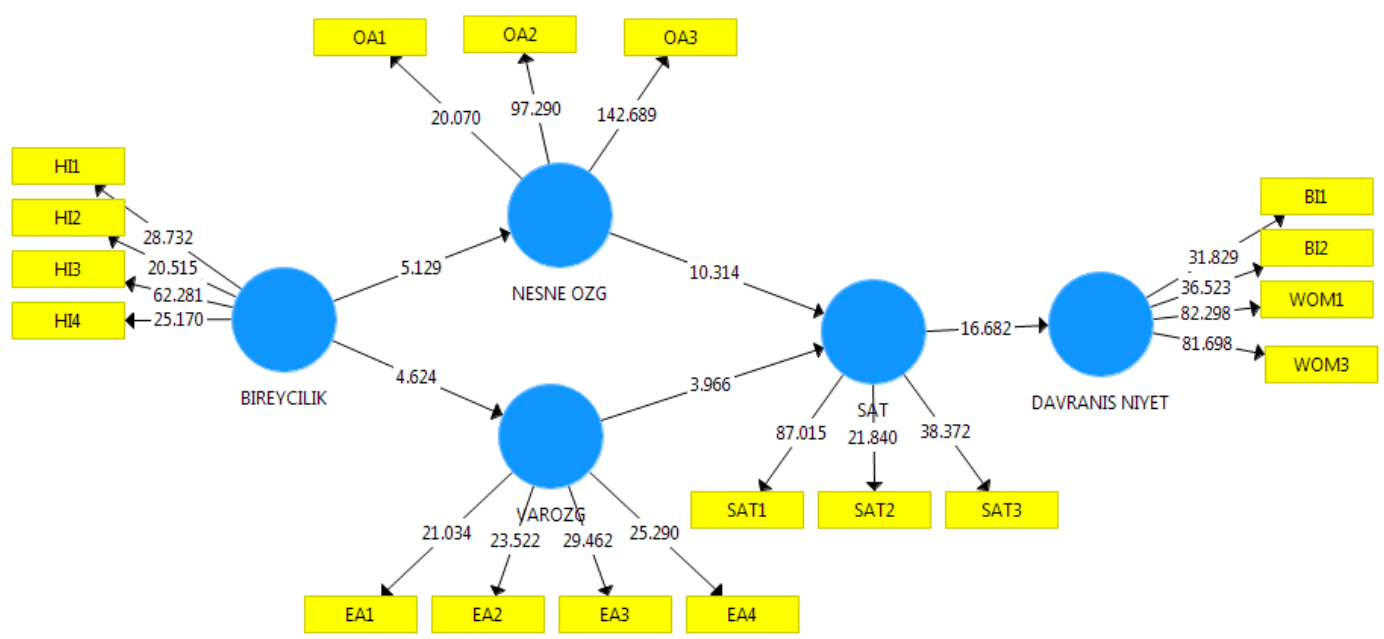

Yapısal modelde yordayıcı yapıların etki büyüklüğünün değerlendirilmesinde Cohen'in $\mathrm{f}^{2}$ etki büyüklüğü değerinin kullanılması önerilmektedir. Etki büyüklüğü, içsel gizil değişkende açıklanamayan varyans oranına göre $R^{2 ' d e k i}$ artışı ile hesaplanmaktadır. Cohen'e göre (1988) $0.35,0,15$ ve $0,02 \mathrm{f}^{2}$ değerleri sırasıyla büyük, orta ve küçük etki büyüklüğü olarak kabul edilmektedir (Peng ve Lai, 2012). Tablo 4 'teki ${ }^{2}$ değerleri incelendiğinde, objeye dayalı özgünlük ile tatmin ilişkisi ve tatmin ile davranışsal niyet arasındaki ilişkilerin yüksek; bireycilik ile objeye dayalı ve varoluşsal özgünlük arasındaki ilişkiler ve varoluşsal özgünlük ve tatmin arasındaki ilişkilerin ise düşük olduğu görülmektedir.

Tablo 4: İçsel model bulguları

\begin{tabular}{lcccc}
\hline Hipotezler & B & $\begin{array}{c}\mathbf{t}- \\
\text { değerleri }\end{array}$ & $\mathbf{f}^{\mathbf{2}}$ & Karar \\
\hline H1: Bireycilik $\rightarrow$ Objeye dayalı Özgünlük & 0,344 & 5,129 & 0,13 & Kabul \\
H2: Bireycilik $\rightarrow$ Varoluşsal özgünlük & 0,211 & 4,624 & 0,04 & Kabul \\
H3: Objeye dayalı özgünlük $\rightarrow$ Tatmin & 0,549 & 10,314 & 0,41 & Kabul \\
H4: Varoluşsal özgünlük $\rightarrow$ Tatmin & 0,161 & 3,966 & 0,06 & Kabul \\
H5: Tatmin $\rightarrow$ Davranışsal niyet & 0,617 & 16,682 & 0,61 & Kabul \\
\hline
\end{tabular}

Etki büyüklüğüne $\left(\mathrm{f}^{2}\right)$ ek olarak, yordayıcı örneklem yeniden kullanma tekniği $\left(Q^{2}\right)$ yordayıcı ilişki düzeyi için bir diğer kriter olarak kullanılmaktadır. Blindfolding prosedürüne dayalı olarak $\mathrm{Q}^{2}$ ölçümü ile, verili bir gösterge bloğu için dışarıda tutulan verilerle karmaşık bir modelin yordayıcı geçerliği değerlendirilmektedir (Ali vd., 2006). Yapısal modelin anahtar öğelerini içerdiğinden, Hair vd. (2017) dışarıda kalan veri noktalarını tahmin etmek için $Q^{2}$ ölçümünde çapraz geçerlenmiş artıklığın (crossvalidated redundancy) kullanılmasını önermektedirler. Bu nedenle bu çalışmada $\mathrm{Q}^{2}$, çapraz geçerlenmiş artıklık prosedürü kullanılarak elde edilmiştir. Eğer $Q^{2}>0$ ise, modelin yordayıcı ilişki düzeyine sahip olduğu ifade edilmektedir (Peng ve Lai, 2012). $Q^{2}$ değerleri objeye dayalı özgünlük, varoluşsal özgünlük, tatmin ve davranışsal niyetler değişkenleri için sırasıyla $0,084,0,023,0,261$ ve 0,244 olarak belirlenmiştir. Bu değerlerin, kabul edilebilir yordayıcı ilişki düzeyini gösterdiği söylenebilmektedir. 


\section{Sonuç ve Öneriler}

$\mathrm{Bu}$ araştırmada, temel olarak özgünlük algısının gerek objeye dayalı olsun gerekse varoluşsal olsun, bireyin içinde yaşadığı kültüre özgü içselleştirdiği değerlerle ilişkili olacağı öngörülmüştür. Araştırma bulguları bu öngörüyü destekler niteliktedir. Çalışmada, bireycilik algılarının, objeye dayalı özgünlük $\left(R^{2}=0,344\right)$ ve varoluşsal özgünlük $\left(R^{2}=0,072\right)$ algıları ile anlamlı bir ilişkisinin olduğu saptanmıştır.

Alanyazında mevcut çalışmalarda, özgünlük algılarına yönelik kültürel normlar ve bireysel standartlar gibi farklı bağlamların belirlediği bir değerlendirme süreci (Yi vd., 2018: 412) olduğu belirtilmekle birlikte, görgül araştırmalar sınırlıdır. Yukarıda elde edilen sonuç, bireycilik değerlerinin özgünlük algılarında etkili olduğunu göstermektedir. Gidilen destinasyon için, özgünlük algılarına bakıldığında; neyin özgün olduğu konusunda bireylerin objelerle kurdukları ilişkinin kişisel deneyimler ve duygular kadar yerel değerler ve sosyal atmosferdende etkilendiği görülmektedir (Yang ve Wall, 2009: 252; Rickly-Boyd, 2013). Öte yandan, bu özellikler, bireyin kendisiyle ve destinasyonda var olan somut ve soyut varlıklarla kurduğu ilişkiyi ifade ederken, toplumsallaşma sürecinde kazandığı bireycilik değerine odaklanmamaktadır.

Bireycilik değerlerinin özgünlük algılarına etkisini daha iyi kavrayabilmek için bu araştırmada yararlanılan, Triandis (2001) modeline yakından bakmanın yararlı olacağı düşünülmektedir. Modelde gerek bireycilik boyutunda, gerekse toplulukçuluk boyutunda yatay ve dikey düzlemler önem kazanmaktadır. Buna göre, bir toplumdaki bireyler, ister bireyci ister toplulukçu yönleri ağır bassın, hiyerarşiye verdikleri önem ya da hiyerarşiye yönelik bilişsel pozisyonları ile birbirlerinden farklılaşmaktadır. Buna göre, dikey bireycilik hiyerarşiyi vurgularken, yatay bireycilik eşitliği vurgulamaktadır (Triandis ve Gelfand, 1998: 119).

Bu çalışmada, yatay bireycilik algılarının hem objeye dayalı özgünlük algılarını hem de varoluşsal özgünlük algılarını etkilediği sonucuna ulaşılmıştır. Yatay bireycilikte bireylerin farklı ve eşşiz bireyliği deneyimlerken, diğer insanlardan, statü, gelir, cinsiyet benzeri özelliklerin hiyerarşisine mesafeli durdukları kaydedilmelidir. Yatay bireycilikte öne çıkan değerler (Triandis ve Gelfand, 1998); kendini diğerleriyle eşit görme, eşitliğe ve özgürlüğe önem vermedir. Bu durum özgünlükle koşutluk göstermektedir. Özgünlük tanımlanırken, bireyin kendine özgü objelerle ve kendi deneyimiyle kurduğu bir ilişki ve oluş durumu olduğu belirtilmektedir (Wang, 1999; Knuddsen vd., 2016; Ram vd. 2016).

Katılımcıların ağırlıklı olarak Kapadokya'ya ilk kez gelişleri ve bireysel olarak ziyaret etmelerinin de bu sonucun doğmasında etkili olduğu düşünülmektedir. Yukarıda da belirtildiği gibi, bireyci kültürlerden gelen kişilerin bireysel seyahate önem vermeleri ve gerek özgünlük algısı ile kültürel değerlerinin kesişmesi sonucun tutarlılığı açısından tamamlayıcı görünmektedir.

Araştırmada ulaşılan bir diğer sonuç ise, objeye ayalı özgünlük ve varoluşsal özgünlüğün tatmin üzerinde anlamlı bir etkisinin bulunmasıdır $\left(R^{2}=0,400\right)$. Bu sonuç, varoluşsal özgünlük algılarının tatmini algılarını etkilediği yönündeki bulgularını teyit etmektedir (Yi vd., 2018; Fu, 2019; Park vd., 2019). Aynı doğrultuda, özgünlük algılarının kültüre miras bağlamında turist algılarını güçlü biçimde etkilediği saptanmaktadır (Lu vd., 2015: 93).

Kişilerin hem objeye dayalı özgünlük hem de varoluşsal özgünlük deneyimlerinin başka bir örneği de özgün ve orijinal yemekler ve yemeklerle ilgili anlatılan öykülerde görülmektedir (Engeset ve Elvekrok, 2014). Le vd. (2019) yaptıkları yazın taramasında 
özellikle yeme deneyimindeki özgünlüğün tatmin üzerinde etkili olduğunu saptayan çalışmalara yer vermektedir. Görüldüğü gibi, yerel ve özgün ürün ve hizmetler kadar bu ürün ve hizmetlerle kurulan ilişkiler de turistlerin tatminleri üzerinde anlamlı bir etkiye sahiptir. Tatmin konusundan elde edilen bu sonuç, turistlerin destinasyonlardan özgünlük beklentilerinin geçerli olduğunu göstermektedir. Kapadokya gibi, kültür turizminin önde olduğu bir destinasyonun sağladığı özgünlük algısı, turistlerin destinasyon tatminlerini anlamlı ölçüde etkilemektedir.

Tatmin algısının turistlerin davranışsal niyetleri üzerinde anlamlı bir etkisi olduğu belirlenmiştir $\left(R^{2}=0,380\right)$. Görgül araştırmalar, özgünlük algılarının bir yere olan yeniden ziyarete etki edeceğini belirlemektedir (Kolar ve Zabkar, 2010; Ramkinsoon ve Uysal, 2011; Casteran ve Roeder, 2013; Meng ve Choi, 2016). Öte yandan, yukarıda da görüldüğü gibi özgünlük algılarının turistlerin tatminini de arttıracağı da belirtilmektedir. $\mathrm{Bu}$ çalışmada ise, tatminin başlı başına davranışsal niyetlerin yordayıcısı olabileceği iddia edilmiş ve görgül olarak sınanmıştır. Sonuç olarak, alanyazınla paralel biçimde (Eusobio ve Viera, 2013; Hultman vd., 2015; Loi vd., 2017; Meng ve Han 2018; Park vd. 2019) tatmin algısının davranışsal niyetler üzerinde etkili olduğunu teyit etmektedir. Önceki araştırmalarda da belirtildiği gibi (Tavitiyaman ve Qu, 2013) turist tatmini turistlerin bir destinasyonu tekrar ziyaret etme ve o destinasyonu tavsiye etme eğilimlerini arttırmaktadır.

Çalışmanın kuramsal katkısının yanı sıra, uygulamaya dönük katkılarının olacağı düşünülmektedir. Çalışmanın sonuçları, belirli bir destinasyonda, özellikle de doğal ve kültürel miras turizmi bağlamında özgünlük arayışının belirlenmesi ile farklı kültürel yönelimlerden gelen turistlere yönelik oluşturulacak ürün ve hizmetlerin tasarımında yön gösterici olacağı umut edilmektedir. Başka bir ifadeyle, turistlerin davranışsal niyetleri, özgünlük arayışlarıyla ilişkilendirilmekte fakat farklı kültürlerden gelen turistlerin beklentilerine yönelik ürün ve hizmetlerin sunulmasında yeterli bilgiyi sağlayamamaktadır.

Çalışmanın, politika yapıcılara ve karar vericilere, farklı turist gruplarına yönelik sundukları ürün ve hizmetlerin oluşturulmasına ve bunların sunumuna katkı sağlayacağı düşünülmektedir. Örneğin, Kapadokya Bölgesi'nde satılan halıların üretiminde ve sunumunda, farklı turist gruplarına yönelik farklı ürün ve hizmet tasarımlarına yönelmek yerinde olacaktır. Üretilen halıların üzerindeki desenlerden, sunum esnasında ikram edilen içeceklere ve kullanılan dile kadar standartlaşmış uygulamalar bireyci ya da toplulukçu kişilerde farklı anlamlar yaratacaktır. Bunun yanında, düzenlenen tur programlarında seçilen mekanların, bu mekanlarda yapılan anlatımların, verilen serbest zamanın niteliği, yatay bireyci ya da dikey bireyci turistler tarafından algılanmasında farklılıklar olacaktır. Sözgelimi, turist rehberlerinin tur katılımcılarına toplu halde bir balonla gezi hizmeti önermesi ile bunu bireylerin seçimine bırakması gibi pratikler toplulukçu ya da bireyci kültürel değerlere yönelen kimselerde farklı etkiler uyandıracaktır. Kapadokya tanıtım filmlerinin hazırlanışından kamuyla paylaşımına kadar her bir adımda söz konusu dengelerin gözden geçirilmesi anlamlı görünmektedir. Örnekleri çoğaltmak mümkündür. Kültürel değerlerin bu yönü, turistlerin yeniden ziyaretleri ile destinasyon deneyimleri hakkındaki görüşlerini etkilemektedir.

Bu kapsamda, ilgili destinasyon yönetimi ve turizm işletmeleri, sundukları ürün ve geliştirdikleri turistik aktiviteleri değerlendirme ve elde edilen sonuçlara göre yeniden bir yapılanma sürecine girmeleri mümkün olacaktır. Özellikle Türkiye'de turizmle ilgili konjonktürel olarak yaşanan kriz durumları dikkate alındığında; Kapadokya özelindeki turizm politikalarının, turistlere sunulan deneyim ve turistik ürünlerin tekrar 
güncellenmesi ve revize edilmesi için elde edilecek bilgilerin yararlı olacağı varsayılmaktadır. Bu çalışma sonucunda katma değere yönelik olarak aşağıda sıralanan faydalar sağlanabilecektir:

- Alanyazında ilk kez bireycilik değişkeninin etkisi özgünlük bağlamında incelenmiştir.

- Kapadokya bölgesini ziyaret eden turistlerin bu destinasyonu ne kadar özgün olarak algıladıkları belirlenmiştir.

- Kapadokya'ya ilişkin turizm politikasının değerlendirilmesine ve ilgili destinasyonda tasarlanacak ürün ve deneyimlerin planlanmasına yön verecek "kültürel farklılıklar" sunulmuştur.

\section{Kaynakça}

Adinegara, G. N. J., Suprapti, N. W. S., Yasa, N. N. K., \& Sukaatmadja, I. P. G. (2017). Factors That Influences Tourist's Satisfaction and Its Consequences. European Journal of Business and Management, 9(8), 39-50.

Domínguez-Quintero, A. M., González-Rodríguez, M. R., \& Roldán, J. L. (2019). The role of authenticity, experience quality, emotions, and satisfaction in a cultural heritage destination. Journal of Heritage Tourism, 14(5-6), 491-505.

Baker, D. A., \& Crompton, J. L. (2000). Quality, satisfaction and behavioral intentions. Annals of tourism research, 27(3), 785-804.

Belhassen, Y., Caton, K., \& Stewart, W.P. (2008) The search for authenticity in the pilgrim experience, Annals of Tourism Research, 35(3), pp. 668-689.

Berman, M. ( 1970). The Politics of Authenticity: Radical Individualism and the Emergence of Modern Society. New York: Atheneu.

Brida, J. G., Meleddu, M., \& Tokarchuk, O. (2017). Use value of cultural events: The case of the Christmas markets. Tourism Management, 59, 67-75.

Castéran, H., \& Roederer, C. (2013). Does authenticity really affect behavior? The case of the Strasbourg Christmas Market. Tourism Management, 36, 153-163.

Chen, C-F., \& Chen, F-S. (2010). Experience Quality, Perceived value, satisfaction and behavioral intentions for heritage tourists. Tourism Management, 31(1), 29-35.

Chhabra, D., Healy, R., \& Sills, E. (2003). Staged authenticity and heritage tourism. Annals of tourism research, 30(3), 702-719.

Cohen, E. (1988). Authenticity and Commodization in Tourism, Annals of Tourism Research, 15, pp. 371-386.

Cohen, E. (2010). Tourism, leisure and authenticity. Tourism recreation research, 35(1), 67-73.

Domínguez-Quintero, A. M., González-Rodríguez, M. R., \& Roldán, J. L. (2018). The role of authenticity, experience quality, emotions, and satisfaction in a cultural heritage destination. Journal of Heritage Tourism, 1-15.

Engeset, M. G., \& Elvekrok, I. (2015). Authentic concepts: Effects on tourist satisfaction. Journal of Travel Research, 54(4), 456-466.

Eusébio, C., \& Vieira, A. L. (2013). Destination attributes' evaluation, satisfaction and behavioural intentions: A structural modelling approach. International Journal of Tourism Research, 15(1), 66-80.

Fu, X. (2019). Existential authenticity and destination loyalty: Evidence from heritage tourists. Journal of Destination Marketing \& Management, 12, 84-94.

Guedes, A. S., \& Jiménez, M. I. M. (2015). Spatial patterns of cultural tourism in Portugal. Tourism Management Perspectives, 16, 107-115.

Hall, C. M. (2007). Current Issues in Tourism Response to Yeoman et al: The fakery of 'The authentic tourist', Tourism Management, 28, 1139-1140. 
Hampden-Turner, C., \& Trompenaars, F. (2011). Riding the waves of culture: Understanding diversity in global business. Hachette UK.

Henseler, J., Hubona, G. ve Ray, P. (2016). Using PLS path modeling in new technology research: updated guidelines. Industrial Management \& Data Systems, 116(1), 2-20.

Hofstede, G. (1980). Culture and organizations. International Studies of Management \& Organization, 10(4), 15-41.

Hofstede, G. (2001). Culture's consequences: Comparing values, behaviors, institutions and organizations across nations. Sage publications.

Hofstede, G., Hofstede, G. J., \& Minkov, M. (2005). Cultures and organizations: Software of the mind (Vol. 2). New York: Mcgraw-hill.

Huang, S. S., \& Crotts, J. (2019). Relationships between Hofstede's cultural dimensions and tourist satisfaction: A cross-country cross-sample examination. Tourism Management, 72, 232-241.

Hultman, M., Skarmeas, D., Oghazi, P., \& Beheshti, H. M. (2015). Achieving tourist loyalty through destination personality, satisfaction, and identification. Journal of Business Research, 68(11), 2227-2231.

Javidan, M., Dorfman, P. W., De Luque, M. S., \& House, R. J. (2006). In the eye of the beholder: Cross cultural lessons in leadership from project GLOBE. Academy of management perspectives, 20(1), 67-90.

Jillian M. Rickly-Boyd (2013) Existential Authenticity: Place Matters, Tourism Geographies, 15:4, 680-686.

Kagitcibasi, C. (1997). Individualism and collectivism. Handbook of cross-cultural psychology, 3, 1-49.

Kim, C. and Lee, S. 2000. Understanding the cultural differences in tourist motivation between Anglo-American and Japanese tourists. Journal Travel and Travel Marketing, 9(1/2): 153-170.

Knudsen D.C., Rickly J.M., Vidon E.S. (2016). The fantasy of authenticity: Touring with Lacan, Annals of Tourism Research, 58 (2016), pp. 33-45.

Kolar, T. and Zabkar, V. 2010. A consumer-based model of authenticity: An oxymoron or the foundation of cultural heritage marketing?. Tourism Management, 31(5): $652-664$.

Korstanje, M. E. (2013). The Obsession With Authenticity: Criticism To Dean MacCannell, Revista Rosa dos Ventos, 5(I) 99-115.

L. Yang, G. Wall (2009). Authenticity in ethnic tourism: Domestic tourists' perspectives, Current Issues in Tourism, 12 (3) , 235-254.

Le, T. H., Arcodia, C., Novais, M. A., \& Kralj, A. (2019). What we know and do not know about authenticity in dining experiences: A systematic literature review. Tourism Management, 74, 258-275.

Lee, S. H., \& Sparks, B. (2007). Cultural influences on travel lifestyle: A comparison of Korean Australians and Koreans in Korea. Tourism Management, 28(2), 505518.

Litvin, S. W., Crotts, J. C., \& Hefner, F. L. (2004). Cross-cultural tourist behaviour: A replication and extension involving Hofstede's uncertainty avoidance dimension. International Journal of Tourism Research, 6, 29-37.

Litvin, S.W. and Kar, G.H. (2003), "Individualism/collectivism as a moderating factor to the self-image congruity concept", Journal of Vacation Marketing, Vol. 10 No. 1, pp. 23-32.

Loi, L. T. I., So, A. S. I., Lo, I. S., \& Fong, L. H. N. (2017). Does the quality of tourist shuttles influence revisit intention through destination image and satisfaction? The case of Macao. Journal of Hospitality and Tourism Management, 32, 115123. 
Lu, L., Chi, C. G., \& Liu, Y. (2015). Authenticity, involvement, and image: Evaluating tourist experiences at historic districts. Tourism Management, 50, 85-96.

MacCannell, D. (1973). Staged Authenticity: Arrangements of Social Space in Tourist Settings. American Journal of Sociology, 79:589-603.

MacCannell, D. 1999: The tourist: a new theory of the leisure class. Berkeley, CA, and Los Angeles, CA: University of California Press.

Markus, H.R., Kitayama, S. (1991). Culture and the self: Implications for cognition, emotion, and motivation. Psychological Review, 98, 224-253.

Matzler, K., Strobl, A., Stokburger-Sauer, N., Bobovnicky, A., \& Bauer, F. (2016). Brand personality and culture: The role of cultural differences on the impact of brand personality perceptions on tourists' visit intentions. Tourism Management, 52, 507-520.

Meng B., Choi K. (2016). The role of authenticity in forming slow tourists' intentions: developing an extended model of goal-directed behavior, Tourism Management, 57 (2016), pp. 397-410.

Meng, B., \& Han, H. (2018). Working-holiday tourism attributes and satisfaction in forming word-of-mouth and revisit intentions: Impact of quantity and quality of intergroup contact. Journal of Destination Marketing \& Management, 9, 347-357.

Olsen, K. (2002). Authenticity as a concept in tourism research: The social organization of the experience of authenticity. Tourist studies, 2(2), 159-182.

Pandža Bajs, I. (2015). Tourist perceived value, relationship to satisfaction, and behavioral intentions: The example of the Croatian tourist destination Dubrovnik. Journal of Travel Research, 54(1), 122-134.

Park, J. Y., Bufquin, D., \& Back, R. M. (2019). When do they become satiated? An examination of the relationships among winery tourists' satisfaction, repeat visits and revisit intentions. Journal of Destination Marketing \& Management, 11, 231239.

Peterson, R. A. (2005). In search of authenticity. Journal of management studies, 42(5), 1083-1098.

Pimtong Tavitiyaman \& Hailin Qu (2013) Destination Image and BehaviorIntention of Travelers to Thailand: the Moderating Effect of Perceived Risk, Journal of Travel \&Tourism Marketing, 30:3, 169-185, DOI: 10.1080/10548408.2013.774911.

Pizam A., Sussmann S. (1995). Does nationality affect tourism behavior?, Annals of Tourism Research, 22 (4), pp. 901-917.

Pizam, A., \& Fleischer, A. (2005). The relationship between cultural characteristics and preference for active vs. passive tourist activities. Journal of Hospitality \& Leisure Marketing, 12(4), 5-25.

Pizam, A., \& Jeong, G. H. (1996). Cross-cultural tourist behavior: Perceptions of Korean tour-guides. Tourism Management, 17(4), 277-286.

Ram Y., Bjork P., Weidenfeld A. (2016). Authenticity and place attachment of major visitor attractions, Tourism Management, 52, pp. 110-122.

Ramkissoon, H., \& Uysal, M. (2011). The effects of perceived authenticity, information search behaviour, motivation and destination imagery on cultural behavioural intentions of tourists. Current Issues in Tourism, 14(6), 537-562.

Reisinger Y. , Turner L.W. (2003). Cross-cultural behaviour in tourism: Concepts and analysis, Butterworth-Heinemann, Oxford.

Reisinger, Y., \& Crotts, J. C. (2010). Applying Hofstede's national culture measures in tourism research: Illuminating issues of divergence and convergence. Journal of Travel Research, 49(2), 153-164.

Rickly-Boyd, J. M. (2012). Authenticity \& aura: A Benjaminian approach to tourism. Annals of Tourism research, 39(1), 269-289.

S.-H. Lee, B. Sparks Cultural influences on travel lifestyle: A comparison of Korean Australians and Koreans in Korea, Tourism Management, 28 (2007), 505-518. 
Steiner, C. J., \& Reisinger, Y. (2006). Understanding existential authenticity. Annals of Tourism Research, 33(2), 299-318.

Tavitiyaman, P., \& Qu, H. (2013). Destination image and behavior intention of travelers to Thailand: The moderating effect of perceived risk. Journal of travel \& tourism marketing, 30(3), 169-185.

Torabian, P., \& Arai, S. M. (2016). Tourist perceptions of souvenir authenticity: An exploration of selective tourist blogs. Current Issues in Tourism, 19(7), 697-712.

Triandis, H. C. (2001). Individualism and collectivism: Past, present, and future. The handbook of culture and psychology, 35-50.

Triandis, H. C., \& Gelfand, M. J. (1998). Converging measurement of horizontal and vertical individualism and collectivism. Journal of personality and social psychology, 74(1), 118.

Trompenaars, F., \& Hampden-Turner, C. (2011). Riding the waves of culture: Understanding diversity in global business. Nicholas Brealey International.

Uçar, M. E., \& Konal, B. (2017). Yatay Dikey Bireycilik/Toplulukçuluk Büyük Beşli Kişilik Özellikleri Ve Benlik Saygısı Arasındaki İlişkiler. Journal Of International Social Research, 10(51).

Urry, J. (1990). The Tourist Gaze. London: Sage.

Veblen, T. (2017). The theory of the leisure class. Routledge.

Vidon, E. S., Rickly, J. M., \& Knudsen, D. C. (2018). Wilderness state of mind: Expanding authenticity. Annals of Tourism Research, 73, 62-70.

Wang, N. (1999). Rethinking Authenticity in Tourism Experience, Annals of Tourism Research, 26, (2), 349-370.

Wasti, S. A., \& Eser Erdil, S. (2007). Bireycilik ve toplulukçuluk değerlerinin ölçülmesi: Benlik kurgusu ve INDCOL ölçeklerinin Türkçe geçerlemesi. Yönetim Araştırmaları Dergisi, 7, 39-66.

Yeoman, I., Brass, D., \& McMahon-Beattie, U. (2007). Current issue in tourism: The authentic tourist. Tourism management, 28(4), 1128-1138.

Yi, X., Fu, X., Yu, L., \& Jiang, L. (2018). Authenticity and loyalty at heritage sites: The moderation effect of postmodern authenticity. Tourism Management, 67, 411424.

Zhang, H., Cho, T., Wang, H., \& Ge, Q. (2018). The influence of cross-cultural awareness and tourist experience on authenticity, tourist satisfaction and acculturation in World Cultural Heritage Sites of Korea. Sustainability, 10(4), 927.

Zhou, Q. B., Zhang, J., Zhang, H., \& Li, X. R. (2018). Is all authenticity accepted by tourists and residents? The concept, dimensions and formation mechanism of negative authenticity. Tourism Management, 67, 59-70. 